\title{
A CASE OF PUERPERAL ECLAMPSIA, WITH AUTOPSY AND REMARKS.*
}

By R. H. BELL, M.A., M.B., B.C. (Cantab.), M.R.C.P. (Lond.)., Obstetric Tutor and Registrar, St. Thomas's Hospital; Physician to Out-Patients, Samaritan Free Hospital for Women.

Comparatively few cases of eclampsia-in England, at any rateare followed by autopsy, with microscopical examination of the organs principally affected, and on this account, as stated by Herman, + our knowledge of the morbid anatomy of the disease is behind that of its cinical phenomena.

In the present instance sections of the liver and kidneys are available for the personal examination and criticism of the Fellows. The macroscopic appearances of the liver can also be studied. It seemed, therefore, worth while to bring the case, although an isolated one, before the Society. For permission to do so I am indebted to Dr. Tate, under whose care the patient was admitted to St. Thomas's Hospital. The clinical history was as follows :

E. M - a a single woman, aged twenty-one, was brought to the hospital, February 26, I902, in a state of coma following a fit. The history of her illness was obtained from her mother. The first definite symptoms occurred about Christmas, Igor. These were severe headache, faintness, swelling of eyelids, and shortness of breath. Swelling of the feet and severe pains in the loins followed.

A doctor saw her for the first time on February 24, and said she had 'dropsy.' He also tested the urine, and said it was 'very bad.' On the 26th she vomited several times, and at $10.30 \mathrm{a} . \mathrm{m}$. the first fit occurred. This was followed by another an hour later. Her mother was then present, and describes it thus: It began by her saying that she could not see anything, then her face went black and twitched; the jaws were clenched. Urine was passed unconsciously, but not fæces. The tongue was bitten, but there were no definite convulsive movements or screaming.

Four more fits occurred before admission to the hospital at 4 p.m., and she was taken up to the ward in a state of coma. A little later she could be made to answer 'yes' or ' no,' but any further attempt to rouse her was resented. On examination there was considerable odema over the whole body, the skin was dry, the

* Read before the Obstetrical Society of London, July 2, 1902.

+ Clifford Allbutt's 'System of Medicine,' vol. vii., article 'Eclampsia.' 
mucous membranes pale. Temperature was $97^{\circ} 8^{\circ}$; pulse, 78 . The breasts were large, with both primary and secondary areolæ; serum was present. The uterus could be felt high in the epigastric region. Evidently the pregnancy was eight months or more. A catheter specimen of the urine showed a heavy trace of albumen.

A fit occurred soon after admission, and lasted five minutes. It was followed by deepened coma and stertorous breathing. Chloral and bromide of potassium (āā 40 grains) were given per rectum, followed a little later by an injection of morphia ( $\frac{1}{2}$ grain).

On vaginal examination the os was found tightly closed, the cervix not obliterated and somewhat hard. The vertex was presenting. The foetal heart was plainly audible.

An hour later the cervix was rapidly dilated under chloroform to a size sufficient to admit De Ribes' bag. No further attempt was made to hasten labour, and the bag was in utero twenty-four hours. During this time the patient remained in a semi-comatose condition, but no fits occurred. The temperature, which soon after admission was $99^{\circ} 6^{\circ}$, rose to $100^{\circ} 6^{\circ}$, and then rapidly, just before delivery, to I04. $8^{\circ}$. Directly the bag was removed forceps were applied, and an easy delivery effected. The placenta was expressed, and appeared normal. An intra-uterine douche was given. There was no excessive bleeding, but shortly after delivery the pulse became weak and running. Intravenous injection of saline (4 pints) caused ternporary improvement only, but upon its repetition a few hours later, combined with a hypodermic injection of strychnine, there was a decided rally, the patient becoming fully conscious. At the time of infusion a few ounces of blood were withdrawn, and were subsequently used in the experiments on toxicity recorded later.

The following morning temperature was $97^{\circ} 8^{\circ}$; pulse, Io8; respirations, 32 per minute; breathing laboured. There was occasional dark brown vomit, slight in amount. The œdema was more marked. The urine was acid, sp. gr. 1,022. Albumen, one-sixth ; no blood, sugar, or deposit. Measurement for the twentyfour hours was 33 ounces. A slight tinge of jaundice was now noticed for the first time. The liver could not be felt ; its area of dulness was normal. There was no hepatic tenderness. The spleen was not felt. Slight shifting dulness was noted in the flanks.

The next day (March I) the condition was very similar, save that the jaundice was more marked. There were no hæmorrhages. The maximum temperature was $100^{\circ} 2^{\circ}$. The bowels had now been well opened by aperients and enemata. The stools were not clay. coloured. 
On March 2 the urine was dark in colour. It contained albumen -still one-sixth only. No attempt was made to distinguish between serum-albumen and paraglobulin. Microscopically some blood-cells were seen (possibly a contamination from the vagina), and a few hyaline and granular casts stained with bile; also some ammonium urate crystals and débris.

An attempt was made to examine the retinæ, but it was found impossible without anæsthesia.

The girl was lying in a semi-comatose condition. The skin

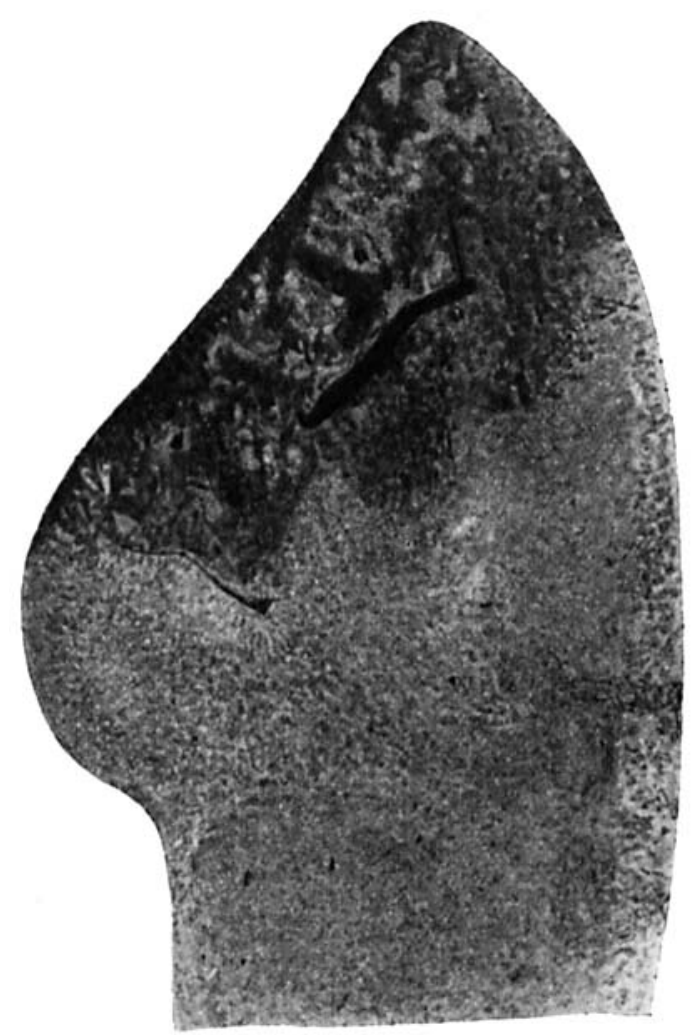

Fig. I.-Naked-eye Appeakances of the Liver. The Section is taken THROUGH THE LARGEST INFARCTED AREA.

being dry and pungent, hot-air baths were ordered, and diaphoresis followed. Towards evening, however, the breathing became worse, and then suddenly the pulse failed. Saline infusion (Io pints) caused a temporary rally, but death took place at I.30 a.m. on March 3. The temperature just before death was Ior $^{*} 4^{\circ}$.

The autopsy took place twelve hours later. It was conducted by Dr. Colman, and the following notes are from his report. I was, unfortunately, unable to be present. 
A utopsy. - The body was very fat. All the tissues were moderately bile-stained.

The liver was not much altered in shape or size, but was extremely flabby. It weighed $55^{\frac{1}{4}}$ ounces. On the anterior margin, and also at the convexity of the right lobe, there were two infarcts, wedge-shaped, firmer than the surrounding tissues, and slightly raised. They were evidently quite recent (a few days), and had a very definite margin. There was no trace of suppuration; there was no blocking of the main trunk of the portal vein.

On section the liver generally was of a dull ochre colour; the outlines of the lobules were not apparent; the whole organ was very friable, and evidently fatty. The affection was uniform. There were no advanced 'red' patches, and the organ, as a whole, was not diminished in size, but there seemed little doubt that the liver was in an early stage of acute yellow atrophy.

The kidneys were not enlarged. The capsule stripped off readily. On section, except for some mottling of the cortex, probably due to fatty change, there was no macroscopic evidence of disease.

The spleen was much swollen. On section it was soft and diffluent.

Heart.-The valves were normal. There were numerous hæmorrhages under the endocardium of the left ventricle, but no other abnormality.

The lungs were healthy. There was calcification of one or two of the bronchial glands, but no recent tubercle anywhere.

The uterus was relaxed. There was a good deal of decomposed clot in its cavity. Fallopian tubes and ovaries were normal.

The brain was not examined.

Portions of the liver and kidney were cut and stained in the clinical laboratory at the hospital. Some of the sections were stained by the ordinary double stain (eosin and hæmatoxylin); others by special stains for fat, such as osmic, sharlach, etc.

Dr. Seligmann, the superintendent of the laboratory, also kindly undertook (with Dr. Russell) the investigation of the toxicity of the blood, and examined a small quantity of urine passed just before death for leucin and tyrosin. I do not propose to give the details of the somewhat complicated chemical method employed, but will simply state the result. Leucin balls were found; tyrosin was not found.

The method adopted to determine the toxicity of the blood was roughly as follows : The blood was received in a clean vessel, and a small quantity of guaiacol added to preserve it. It was kept in an 
ice chamber for some weeks, and then the clear serum was injected into a guinea-pig, the method employed being that of subcutaneous injection.

For purposes of comparison the blood withdrawn from two cases of uræmia, in hospital at the same time, was examined. One case may be shortly described. He was a man, aged 32 , suffering from fits and subsequent coma. The urine contained hyaline, granular, and fatty casts. No blood. Albumen 2 grammes per litre. Urea 4 grains per ounce. The arteries were thickened. Post-mortem the kidneys were seen to be small, the capsule stripped, but the surface

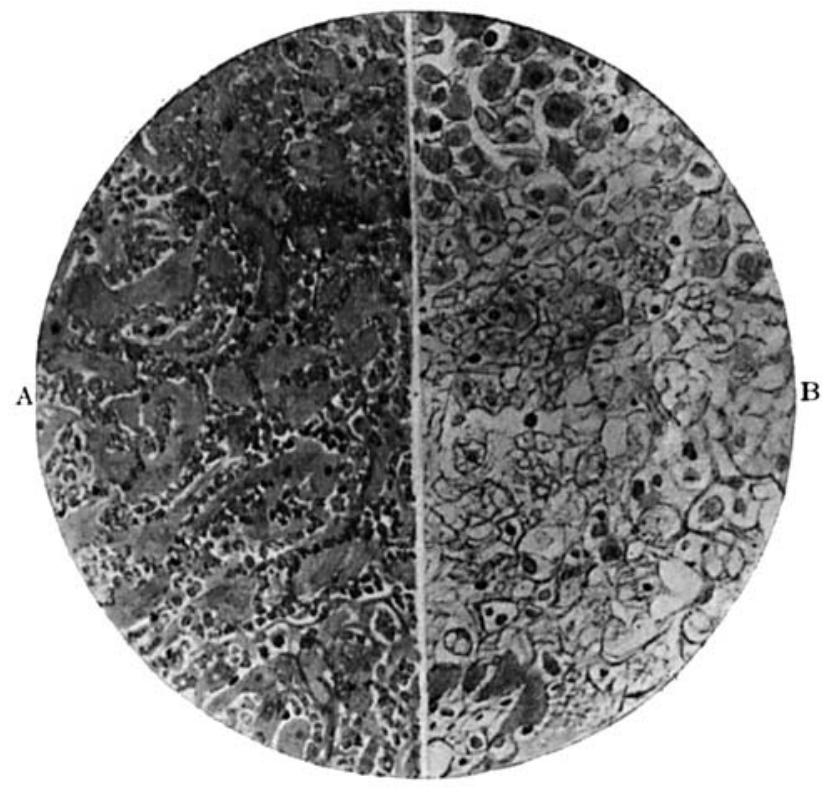

FIG. 2.-Liver.

$A$, section showing degenerative changes-the spaces were for the most part filled with fat; $B$, section through infarcted area.

was granular. The cortex was soft, pale, and dirty yellow. The liver was engorged and fatty. There was hypertrophy of the left ventricle. It was a case of chronic nephritis, with the most marked changes occurring in the convoluted tubes.

The other case was rather a chronic ' interstitial ' nephritis, with the clinical phenomena of chronic uræmia.

Five c.c. of the 'eclamptic' blood were injected into two guineapigs, weighing respectively 170 and $205 \mathrm{grm}$. Both animals died in less than twenty-four hours. Post-mortem there were no very obvious naked-eye changes. The toxicity of the blood-serum was 
therefore $2^{\cdot} 5$ per cent., or, at least, it was not more than this, though possibly less.

The comparison was made by injecting roughly proportionate quantities of serum from the cases of chronic uræmia.

The actual quantities used were-

(a) 9 c.c. from case of chronic tubal nephritis injected into guinea-pig weighing $287 \mathrm{grm}$.

(b) 6 c.c. from case of chronic interstitial nephritis injected into guinea-pig weighing $220 \mathrm{grm}$.

In neither case did death follow ; in fact, the only visible change produced was a certain loss of briskness.

The microscopic appearances will now be shortly described.

Liver.-(a) Low power. The outlines of the lobules are for the most part fairly distinct. There is little cell infiltration round the interlobular vessels, which are not thrombosed. The cells are faintly stained and vacuolated. Although the change is fairly uniform, it is most marked in the central zone of the lobule.

(b) High power. The cells are seen to present various stages of degeneration. In those least affected the nucleus is still present, and stains fairly well with hæmatoxylin. The protoplasm is granular and contains a number of fatty masses, or appears vacuolated, the spaces being, no doubt, due to the dissolving out of fat. These cells are mostly situated at the periphery of the lobule. More centrally there is extreme degeneration. The nuclei are very faintly marked, or exist as fragments only. The protoplasm has shrunk, and is vacuolated. In many of these cells, indeed, no nucleus is to be seen, and the protoplasm is represented by a few irregular strands stretched across the cell.

The connective-tissue cells have not degenerated, and their nuclei stain well, suggesting a possibly fictitious increase in their number.

There is a desquamative catarrh of the bile-ducts, the epithelium being shed and in places blocking the lumen, but the cells are apparently not themselves degenerate.

The sections stained with osmic appear almost uniformly black, and microscopically the greater part of the cells are seen to be almost entirely filled with fat.

Kidney.-(a) Low power. The changes are most marked in the cortex. The majority of the convoluted tubules are seen to be affected. The protoplasm of their cells is clouded. The cells thems:lves often contain no nuclei, so that whole transverse sections of tubules may be observed with one, two, or even no nuclei.

The glomeruli seem for the most part unaffected, and the wide 
space sometimes present between them and Bowman's capsule is probably due to defective preparation. In the medullary rays the loops of Henle appear practically normal. The connective tissue is not increased, and there is little or no infiltration of leucocytes. The capsule is not thickened.

(b) High power. In the tubules in which nuclei are present the cells are seen to be granular. In those in which the nuclei are not differentiated they are not only granular, but also the part of the cell towards the basement membrane is for the most part occupied by fairly large discrete fatty globules.

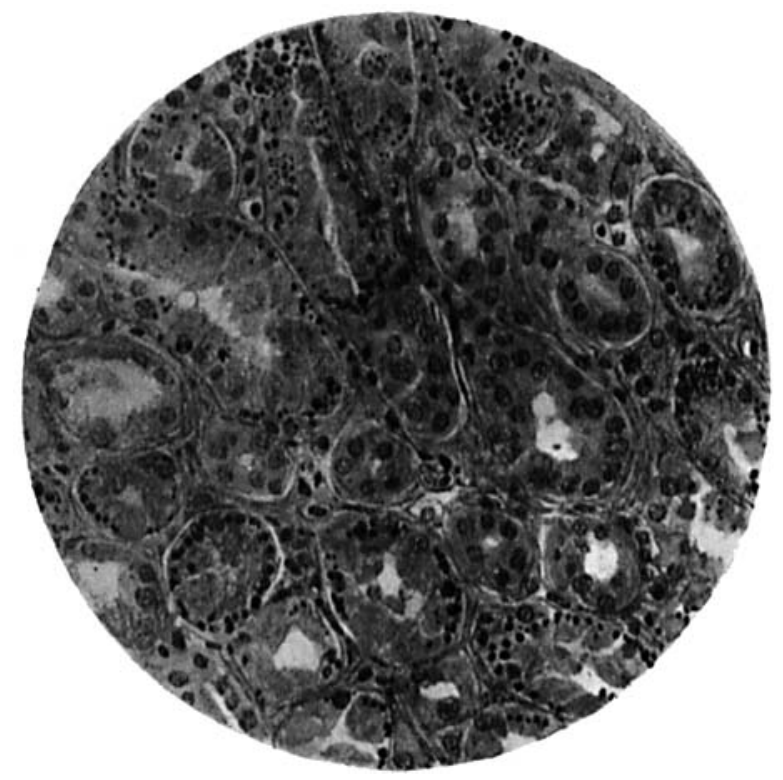

Fig. 3.-Kidney, Strained with Neutral Red and Osmic Acid, showing Granular and Falty Degeneration of the Convoluted Tubes.

In a few tubules there is desquamation of epithelium, and here and there it seems as if there was an attempt at the formation of new epithelium. Although the glomeruli are little affected, a few cells appear vacuolated, with their nuclei stained irregularly. There is no trace of a fatty change.

Remarks.-I do not propose to enter into any discussion of the treatment of eclampsia. Morphia, induction of labour, saline infusions, etc., were all tried, but without success. The clinical history is interesting, and has been detailed at some length; but the main interest of the case lies in the autopsy, and the light which it throws on the pathology of the disease.

Speaking generally, the post-mortem signs were those of a case of 
acute yellow atrophy of the liver in an early stage. It was, in fact, so described by Dr. Colman at the head of his report; but, clinically, it was a case of eclampsia. It is true that shortly before death the skin became jaundiced and the urine high coloured. But the occurrence of jaundice in cases of eclampsia is now well recognised. In the discussion on eclampsia at the meeting of the German Society for Gynæcology at Giessen in May, Igor (reported in the Centralblatt für Gynäkologie, June, I901, p. 700), Schmorl of Dresden, in an analysis of seventy-three cases, with autopsies, mentions that icterus was present in ten cases, and that in three of these the clinical symptoms suggested the diagnosis of acute yellow atrophy; but he adds that exactly the same changes were found in the liver as in the cases of eclampsia without jaundice, and he goes on to deprecate any separate classification of the cases where jaundice occurred.

The onset of the illness must also be remembered-headache, vomiting, dyspnœa, and dropsy, culminating finally in fits and coma. When admitted to the hospital, she was comatose, with marked general cedema and albumen (one-sixth), but no jaundice or other indication of acute yellow atrophy.

It must be admitted that the urinary changes were not characteristic. The exact quantity of urine passed was difficult to measure, but certainly it was little diminished from the normal. On two days the amount measured was respectively 33 ounces and $4^{\circ}$ ounces. Albumen was always present in considerable quantity, but never more than one-sixth. I regret that there was no estimation of urea.

It should be noted, too, that the liver dulness was not diminished, and that after death the organ was found little altered in shape or size, and weighed $55 \frac{1}{4}$ ounces.

With regard to the microscopical characters, I would call attention to the following points: (I) There was none of the infiltration round the portal vessels and formation of embryonic fibrous tissue which has been described in acute yellow atrophy-at least, in advanced stages of the disease; (2) the degeneration of the individual cells is most marked at the centre rather than at the periphery of the lobule; and (3) the amount of fat present is far more than is usually seen in acute yellow atrophy, where the granular débris is in excess of the fat.

The lesions are characteristic not so much of acute yellow atrophy as of some acute toxæmia.

Since Pilliet described them in I 889 similar changes have been found in almost all cases of eclampsia where the liver has been subjected to microscopical examination. They were present to a greater or less degree in seventy-one of the seventy-three cases referred to 
by Schmorl in the discussion at Giessen previously mentioned, and their resemblance to those of acute yellow atrophy and phosphorus poisoning has often been pointed out. The question of phosphorus poisoning need not, I think, be considered in this case. There was no reason to suspect it, and the history of the onset is against the diagnosis.

It is perhaps permissible to suggest that the distinction between eclampsia and acute yellow atrophy occurring in a pregnant woman is of no very great importance. The latter is, after all, only a name describing a certain morbid condition of the liver found post-mortem, and produced by some toxic agent or agents at present unknown. Puerperal eclampsia, too, is now very largely regarded as a toxic disease, though the toxin remains undiscovered and its source un. certain.

But from reading the English text-books and the discussion in this Society last year on Dr. Hey Groves' paper, there would seem to be some confusion and considerable difference of opinion. It is doubtful whether at least two classes of cases are not commonly described under the heading of eclampsia: (I) where the kidney is primarily at fault, and the case is one of poisoning due to imperfect elimination of toxins; and (2) where the production or absorption of toxins is excessive.

In the first case the lesions post-mortem are most marked in the kidney, and are primarily of an inflammatory character. The disease is really uræmia, occurring during pregnancy.

In the second case the most characteristic lesions are in the liver, and are degenerative, the kidney showing similar changes, but to a less extent.

The case here recorded seems to me to belong to the latter class, and to be very closely allied to acute yellow atrophy. Perhaps we have reached the stage when the term 'eclampsia' might be given up, and all such cases considered and reported under the heading 'puerperal toxæmia,' while recognising that the actual toxin or toxins have still to be discovered.

I have not ventured to adopt this heading myself, but it has been done already in America-for example, by McCone, in a short article in the American Journal of Obstetrics for May, Igo2.

That the blood in this case was very highly toxic is proved by the experiments of Dr. Seligmann. Certanly, in a recent paper, Eden* has criticised the methods adopted for determining the

* Journal of Obstetrics and Gynacology, February, I902, p. 192. 


\section{Journal of Obstetrics and Gynæcology}

toxicity of urine and blood-serum, and has pointed out especially how the experiments of Stewart proved that the older results, where care was not taken to prevent contamination, might be practically disregarded. Some of the later results seem, however, to be generally accepted-e.g., those of Tarnier and Chambrelent, who in two cases of eclampsia found the toxicity of the blood-serum to be from $3^{*} 3$ to $4^{*} 3$ per cent., that of normal blood-serum being ro per cent.i.e., in the one case $3 \cdot 3$ c.c. would kill Ioo grammes of rabbit, while in the other case it would require Io c.c.

In the case here reported, if the precautions used justify one in accepting the result, as I assume, the toxicity of the blood was even greater than in either of Tarnier and Chambrelent's cases; 5 c.c. of blood-serum was sufficient to kill, first, 170 grammes of guinea-pig, and then, in a later experiment, 205 grammes, which is equivalent to a toxicity respectively of 2.94 and 2.5 per cent. The fact that guinea-pigs were employed by Dr. Seligmann, while Tarnier and Chambrelent used rabbits, may to some extent vitiate the comparison, but the high degree of toxicity is made especially apparent by the control experiments with blood from cases of chronic uræmia.

Where the 'eclamptic' blood had caused death in less than twenty-four hours proportionate doses of 'uræmic' blood produced only loss of briskness. So far, therefore, as one comparison can carry us this would seem to indicate that the blood-serum of a patient suffering from 'puerperal eclampsia' has a considerably greater toxicity than that drawn from ordinary cases of uræmia, even in the stage of coma.

\section{ADDENDUM.}

Since reading the above further sections have been cut through different portions of the liver, including the infarcted area. The appearances in the latter case are shown in the illustration (Fig. 2, B). The other sections show to a greater or less extent the degenerative changes already detailed (Fig. 2, A).

The other drawing accompanying this paper indicates the microscopic appearances of the kidney.

The occurrence of hæmorrhagic infarction in the liver is so rare that one hesitates to declare that the condition found here was one of true infarction, especially as no thrombosis or embolism could be demonstrated either macroscopically or microscopically in the branches of the hepatic artery or of the portal vein. So far as I 


\section{Bell : Puerperal Eclampsia}

know, true infarction has not been recorded in connection with eclampsia, while hæmorrhages into the substance of the liver are a well-known feature of the disease. At the same time, the somewhat wedge-shaped area of fairly definite outline, with one boundary formed by the surface of the liver, is very suggestive of infarction. as are also the microscopic appearances. The liver cells lying in the interstices of the hæmorrhage stain uniformly, have lost their definite outline, and in most cases their nuclei, and are apparently in a condition of coagulative necrosis. It should, however, be mentioned that in one section, through a very degenerate portion of the liver, there was a small hæmorrhage, not larger than a pin's head, and the microscopic appearances were exactly the same as in the case of the large 'infarction.' I think the question whether the large hæmorrhagic areas were true infarctions or not must be left open. I should add that the liver has been referred to the Pathological Committee of the Obstetrical Society of London for further investigation 